NBER WORKING PAPER SERIES

ON THE OPTIMAL CHOICE OF A MONETARY POLICY INSTRUMENT

\author{
Andrew Atkeson \\ V. V. Chari \\ Patrick J. Kehoe \\ Working Paper 13398 \\ http://www.nber.org/papers/w13398
}

\author{
NATIONAL BUREAU OF ECONOMIC RESEARCH \\ 1050 Massachusetts Avenue \\ Cambridge, MA 02138 \\ September 2007
}

Atkeson, Chari, and Kehoe thank the National Science Foundation for financial support, Jon Faust and Nancy Stokey for useful discussions, particularly Stokey's [2003] discussion of an earlier draft of this work, and Kathleen Rolfe and Joan Gieseke for excellent editorial assistance. The views expressed herein are those of the authors and not necessarily those of the Federal Reserve Bank of Minneapolis or the Federal Reserve System. The views expressed herein are those of the author(s) and do not necessarily reflect the views of the National Bureau of Economic Research.

(C) 2007 by Andrew Atkeson, V. V. Chari, and Patrick J. Kehoe. All rights reserved. Short sections of text, not to exceed two paragraphs, may be quoted without explicit permission provided that full credit, including $\odot$ notice, is given to the source. 
On the Optimal Choice of a Monetary Policy Instrument

Andrew Atkeson, V. V. Chari, and Patrick J. Kehoe

NBER Working Paper No. 13398

September 2007

JEL No. E3,E31,E4,E42,E51,E52,E58,E6,E61

\author{
$\underline{\text { ABSTRACT }}$ \\ The optimal choice of a monetary policy instrument depends on how tight and transparent the available \\ instruments are and on whether policymakers can commit to future policies. Tightness is always desirable; \\ transparency is only if policymakers cannot commit. Interest rates, which can be made endogenously \\ tight, have a natural advantage over money growth and exchange rates, which cannot. As prices, interest \\ and exchange rates are more transparent than money growth. All else equal, the best instrument is \\ interest rates and the next-best, exchange rates. These findings are consistent with the observed instrument \\ choices of developed and less-developed economies. \\ Andrew Atkeson \\ Bunche Hall 9381 \\ Department of Economics \\ UCLA \\ Box 951477 \\ Los Angeles, CA 90095-1477 \\ and NBER \\ andy@atkeson.net \\ V. V. Chari \\ Department of Economics \\ University of Minnesota \\ Minneapolis, MN 55455 \\ and NBER \\ chari@res.mpls.frb.fed.us \\ Patrick J. Kehoe \\ Research Department \\ Federal Reserve Bank of Minneapolis \\ 90 Hennepin Avenue \\ Minneapolis, MN 55480-0291 \\ and NBER \\ pkehoe@ res.mpls.frb.fed.us
}


What is the best instrument for conducting monetary policy-interest rates, exchange rates, or money growth rates? The answer to this classic question depends heavily on two instrument characteristics: tightness and transparency. One instrument is tighter than another if it is more closely linked to the feature it is meant to influence-here, inflation. An instrument is more transparent if it better reveals the actions of the government to the public. Using a standard representative agent model, we argue that tightness is always desirable in an instrument and that transparency is desirable only if the policymaker cannot commit to future policies.

This argument has clear implications for the optimal choice of a monetary policy instrument. The tightness of interest rates is endogenously determined, while that of the other instruments is exogenous. Endogenous tightness allows policies to be structured so as to give interest rates a natural advantage over both money growth and exchange rates in environments with and without commitment. With regard to transparency, we follow the literature and argue that, because they are prices, interest rates and exchange rates are more transparent than money growth. We show that this greater transparency gives interest and exchange rates a natural advantage over money growth in an environment without commitment. Thus, in any environment, interest rates have natural advantages over exchange rates and money growth, while in some environments, exchange rates have natural advantages over money growth. Our analysis implies that, all else equal, interest rates are the best monetary policy instrument and exchange rates, the next-best instrument.

These findings offer insights into observed policy choices across economies. Developed economies have generally used the model's preferred instrument, interest rates, as their primary policy instrument. In less-developed economies, financial markets tend to function poorly, so interest rates are often not an instrument option. Instead of money growth, therefore, these economies have tended to use the model's next-best choice, exchange rates.

Our work here contributes directly to the literature on optimal monetary policy instruments. The idea that tightness is desirable in an instrument dates at least to the classic analysis of Poole [1970]. He shows that the desirability of interest rates as an instrument relative to money growth rates depends only on the relative variability of exogenous shocks. His model has no forward-looking features and thus has a unique equilibrium even under an interest rate policy. Sargent and Wallace [1975] show that in models with forward-looking private agents, 
interest rate rules that depend only on the history of exogenous shocks lead to indeterminacy of equilibria, but money rules lead to unique equilibria. Sargent and Wallace argue that this indeterminacy makes it risky to use interest rates as an instrument and hence gives money growth policies a natural advantage over interest rate policies.

McCallum [1981] and Woodford [2003] enrich the space of interest rate policies beyond that considered by Sargent and Wallace by allowing these policies to depend on the history of past actions as well as on the history of exogenous shocks, but restrict them to be the same on and off the equilibrium path. With such restricted policies, McCallum and Woodford show that equilibria need not be indeterminate. For example, Woodford considers a class of Taylor rules and shows that equilibria are determinate if and only if the policy satisfies the Taylor principle: the central bank should raise its interest rate more than one-for-one following an increase in expected inflation. More precisely, Woodford shows that if the policy satisfies the Taylor principle, the economy has a unique equilibrium, while if it violates that principle, the economy has a continuum of equilibria.

We make two contributions to this literature. One is to show that indeterminacy under interest rate rules can be completely eliminated by further enriching the policy space to allow sophisticated policies, by which we mean policies that can differ on and off the equilibrium path. In our model, this enrichment is particularly desirable because the policy associated with the best equilibrium violates the Taylor principle. Within the class of policy rules considered by Woodford [2003], the best outcome lies in the indeterminate region, while with our sophisticated policies, the best outcome can be implemented as a unique equilibrium. (For different proposed resolutions to the indeterminacy issue, see Bassetto [2002] and Adão, Correia, and Teles [2006].)

In effect, we have turned the Sargent and Wallace [1975] criticism of interest rate policies on its head. Sargent and Wallace argue that equilibrium indeterminacy gives interest rates a natural disadvantage relative to money growth rates as an instrument. We show that this indeterminacy implies that the tightness of interest rates varies endogenously with the equilibrium. A sophisticated specification of interest rate policies that exploits the endogenous tightness supports a unique equilibrium with the best outcomes. Thus, endogenous tightness gives interest rates a natural advantage over money growth rates.

Our other contribution is to formalize the idea that more transparent instruments have a 
natural advantage over less transparent ones. That idea is widely held, especially about market prices like interest rates and exchange rates. Calvo and Végh [1999, p. 1589], for example, argue:

By the simple virtue of being a price rather than a quantity, the exchange rate provides a much clearer signal to the public of the central bank's intentions and actual actions than a money supply target.

Clearly, Calvo and Vegh's [1999] comment applies equally well to the greater transparency of interest rates over money growth rates. Yet, even though Persson and Tabellini [1994] agree that the exchange rate is more transparent than money growth, they speak for many when they point out the need to formalize the idea that more transparent instruments have a natural advantage over less transparent ones. Referring to the exchange rate, Persson and Tabellini [1994, p. 17] write:

In particular, it is easily observable, so the private sector can directly monitor any broken promises by the central bank. But we know of no convincing argument that turns these properties into an explanation for why it would be a more efficient method to achieve credibility to target the exchange rate rather than, say, the money growth rate.

Here we provide what we think is that convincing argument.

We establish our results regarding the desirability of tightness and transparency in a simple monetary model (that of Woodford [2003]). This model has a Phillips curve that links output to unexpected inflation and an Euler equation that links growth rates in output to real interest rates. The Euler equation is subject to distortionary shocks. We enrich the model by including a relationship between (intended) money growth and inflation that is subject to random shocks and a purchasing power relationship that links domestic inflation, the change in the exchange rate, and foreign inflation.

We first analyze the optimal instrument choice in an environment in which the policymaker can commit to its future policies. We say that the transparency of money is irrelevant if, for all parameter values, the optimal instrument is the same both when money is opaque and when 
it is transparent. We show that the transparency of money is irrelevant under commitment in this sense. Regardless of whether money growth is observed or not, the central bank commits to a policy rule at the beginning of time, and deviations from that rule are simply prohibited. Hence, the central bank has no incentive constraints for which the lack of observability of its action may be relevant.

We then turn to an analysis of tightness under commitment. In our model, the tightness of money growth and exchange rates is exogenous. When these are the only instruments available, the analysis is similar to that of Poole [1970], and the tighter instrument is preferred. In terms of the tightness of interest rates, we show that when policies are restricted to be the same on and off the equilibrium path and when the Taylor principle is violated, the equilibria are indeterminate. The best equilibrium has a policy rule that violates the Taylor principle on the equilibrium path. The associated outcome has lower variability of output and inflation than any of the equilibria that satisfy the Taylor principle and has higher welfare.

This best outcome is supported as a unique equilibrium by sophisticated policies, in which if private agents deviate from the best outcome, the central bank switches policies in such a way as to make it not optimal for any individual private agent to deviate. In particular, after a deviation, the central bank chooses policies so that the original choice is optimal for each private agent. Thus, even if an individual private agent believes that all other private agents have deviated, this agent will choose not to deviate. Hence, no such deviations can occur, and the equilibrium is unique.

We then turn to an analysis of the role of transparency in an environment in which the policymaker cannot commit to its future policies. Here we find it notationally convenient to focus on the choice between money and exchange rates. The analysis of other prices, like interest rates, is nearly identical.

We model the idea of Persson and Tabellini [1994], Calvo and Végh [1999], and others that exchange rates are transparent and money growth is opaque as follows. We assume that agents can see the exchange rate. We follow Cukierman and Meltzer [1986] and Faust and Svensson [2001, 2002] in assuming that when the central bank uses money as its instrument, it chooses an action, which is not directly observed by private agents, referred to as intended money growth. Private agents observe the actual growth rate of the monetary aggregate, which 
depends on intended money growth as well as on domestic shocks to the financial system.

The intuition for our results regarding transparency is as follows. Our model has a time inconsistency problem in that using either instrument, without commitment, the central bank has a temptation to surprise the public with higher than expected inflation in order to decrease unemployment. In order to achieve a good outcome, the equilibrium strategies must provide incentives for the central bank to resist the temptation by providing high payoffs when it chooses low inflation and low payoffs when it chooses high inflation. With a transparent instrument, any deviation is perfectly detectable, and along the equilibrium path, only high payoffs will occur. With an opaque instrument, however, to deter deviations to high money growth, the equilibrium strategies must ensure that high realizations of inflation are followed by low payoffs for the central bank. Since high realizations of inflation will occur even if the central bank does not deviate, with such strategies at least some period of low payoffs for the central bank must be realized in equilibrium. Thus, when both instruments are equally tight, the transparent one is preferred.

Our analysis is related to several literatures beyond those mentioned above. Our analysis of tightness incorporates the classic Mundellian trade-off between using the money growth rate and using the exchange rate as the monetary instrument. (For a recent model with such a trade-off, see the work by Alesina and Barro [2002] on currency unions.)

Our analysis of transparency is related to that of Canzoneri [1985], who assumes that a private information problem arises under a money regime because the money growth rate is an opaque instrument. Canzoneri [1985] focuses on characterizing equilibrium outcomes when money growth is an opaque instrument. Our focus is on the role of transparent and opaque instruments. ${ }^{1}$

Our analysis is most closely related to the work of Herrendorf [1997] and Stokey [2003]. Herrendorf [1997] considers an optimal taxation game in which the monetary authority must finance a given amount of spending with a combination of direct taxes and inflation taxes. The monetary authority can choose a transparent fixed exchange rate regime in which it must set some fixed suboptimal exchange rate peg or an opaque money regime in which it is free to choose any rate of money growth. ${ }^{2}$ Stokey [2003] builds on our analysis from an earlier draft of our work here, but focuses on using simple two-state Markov perfect equilibria and shows how 
to solve for the best equilibria in this class under either a money regime or an exchange rate regime.

Finally, our recursive method for analyzing a monetary model is related to that of Chang [1998].

\section{The Model}

The model we use to analyze the optimal choice of a monetary policy instrument is a modified version of a standard, linearized model of monetary policy.

\section{I.A. The Determinants of Output \& Inflation}

In the model, time is discrete, and periods are denoted $t=0,1,2, \ldots$ The economy consists of a continuum of private agents and a central bank. The economy's output in any period $y_{t}$ is determined by a Phillips curve

$$
y_{t}=\pi_{t}-x_{t},
$$

where $\pi_{t}$ is the economy's inflation rate from period $t-1$ to $t$ and $x_{t}$ is the (change in the) average wage.

The relationship between domestic inflation $\pi_{t}$ and the rate of change in the exchange rate $e_{t}$ is given by

$$
\pi_{t}=e_{t}+\pi_{t}^{*}
$$

where $\pi_{t}^{*}$ has a normal distribution with mean 0 and variance $\sigma_{\pi^{*}}^{2}$. The variable $\pi_{t}^{*}$ reflects a combination of inflation in foreign economies and shocks to the real exchange rate (that is, deviations from purchasing power parity). For simplicity, we refer to $e_{t}$ as the exchange rate and $\pi_{t}^{*}$ as foreign inflation. We let $g\left(\pi_{t} \mid e_{t}\right)$ denote the density of domestic inflation given the choice of exchange rate $e_{t}$.

We let $\mu_{t}$ be the central bank's intended growth rate of money. The relation between intended money growth $\mu_{t}$ and inflation is

$$
\pi_{t}=\mu_{t}+\varepsilon_{t},
$$


where $\varepsilon_{t}$ represents domestic shocks that are normally distributed with mean 0 and variance $\sigma_{\varepsilon}^{2}$. We let $f\left(\pi_{t} \mid \mu_{t}\right)$ denote the density of domestic inflation given the choice of the intended money growth rate $\mu_{t}$.

Interest rates $i_{t}$ enter the model through a linearized intertemporal Euler equation

$$
y_{t}=E_{t}\left[y_{t+1}\right]-\sigma\left(i_{t}-E_{t}\left[\pi_{t+1}\right]\right)+\eta_{t}
$$

where $\eta_{t}$ is an i.i.d. mean zero normal shock with variance $\sigma_{\eta}^{2}, \sigma$ determines the intertemporal elasticity, and $E_{t}$ denotes the expectations of a representative agent given that agent's information in period $t$, which includes the shock $\eta_{t}$.

At the beginning of each period, the central bank chooses to operate under one of three regimes: the (crawling peg) exchange rate regime, the money regime, or the interest rate regime. In the exchange rate regime, the central bank sets $e_{t}$; in the money regime, $\mu_{t}$; and in the interest rate regime, $i_{t}$. Notice that in both the exchange rate and money regimes, the central bank effectively chooses the mean inflation rate, and the variance of this inflation rate is determined by shocks outside of the central bank's control. In the interest rate regime, the inflation rate is not directly under the central bank's control. It is determined by the equilibrium conditions. In all three regimes, (1)-(4) hold, and the unchosen variables are residually determined.

\section{I.B. Payoffs}

Letting $z_{t}$ denote the representative agent's individual wage rate and recalling that $x_{t}$ denotes the corresponding average rate of wage change, we let the representative agent's perperiod payoff for given values of $z_{t}, x_{t}$, and a realization of $\pi_{t}$ be

$$
r^{A}\left(z_{t}, x_{t}, \pi_{t}\right)=-\frac{1}{2}\left[\left(z_{t}-\pi_{t}\right)^{2}+\left(y_{t}-\bar{y}\right)^{2}+\pi_{t}^{2}\right],
$$

where $\bar{y}$ is the preferred level of output. Note, from the right side of (5), that the payoff depends on the unexpected changes in this agent's real wages and the domestic economy's output and inflation. The representative agent's utility is the expected value of the discounted per-period payoff:

$$
\sum_{t=0}^{\infty} \beta^{t}(1-\beta) r^{A}\left(z_{t}, x_{t}, \pi_{t}\right)
$$

where $\beta$ is the discount factor and we have normalized the per-period payoff by $(1-\beta)$. The central bank seeks to maximize the representative agent's utility. 


\section{I.C. Tightness \& Transparency}

Here we define more precisely our notions of tightness and transparency of alternative monetary policy instruments.

One measure of the extent of control associated with an instrument is the variability of inflation conditional on the instrument, namely, $\operatorname{var}\left(\pi_{t} \mid e_{t}\right), \operatorname{var}\left(\pi_{t} \mid \mu_{t}\right), \operatorname{var}\left(\pi_{t} \mid i_{t}\right)$. We say that one instrument, say, the money growth rate, is tighter than another instrument, say, the exchange rate, if and only if, for all periods, for the same mean inflation rate, the conditional variance of inflation is less with the money instrument than with the exchange rate instrument, that is, when $\operatorname{var}\left(\pi_{t} \mid \mu_{t}\right)<\operatorname{var}\left(\pi_{t} \mid e_{t}\right)$ with $E\left(\pi_{t} \mid \mu_{t}\right)=E\left(\pi_{t} \mid e_{t}\right)$ for all $t$. Note from (2) and (3) that money growth rates are tighter than exchange rates if and only if $\sigma_{\varepsilon}^{2}<\sigma_{\pi^{*}}^{2}$. Clearly, the tightness of both exchange rates and money growth rates is exogenous in the sense that it is independent of the particular policy chosen. This property holds because (2) and (3) imply a static relation between the instrument and inflation. In contrast, the tightness of interest rates is endogenous in the sense that the conditional variance $\operatorname{var}\left(\pi_{t} \mid i_{t}\right)$ depends on the particular policy chosen. As we show below, this property holds because the relation between inflation and this instrument is an intertemporal one and depends on the expectations of private agents.

Persson and Tabellini [1994], Calvo and Végh [1999], and others consider exchange rates to be more transparent than money growth rates because exchange rates are easier for the public to monitor. One motivation for this assumption is the observation that private agents deal with these prices in their day-to-day affairs, essentially obtaining information about these monetary policy instruments at no cost. Acquiring and interpreting information about monetary aggregates is, by comparison, costly.

We assume that under both regimes, agents can see the exchange rate $e_{t}$, the interest rate $i_{t}$, and the domestic inflation rate $\pi_{t}$ but not the intended money growth rate $\mu_{t}$. Thus, under an exchange rate regime, for example, agents directly see the actions of the central bank, while under a money regime, they see only a noisy signal of the central bank's actions. We thus refer to exchange rates and interest rates as transparent instruments and to the money growth rate as the opaque instrument.

A plausible interpretation of our opaqueness assumption is that monetary aggregates do not perfectly reveal the actions of the central banks, referred to, again, as intended money 
growth. (This interpretation follows that of Cukierman and Meltzer [1986] and Faust and Svensson [2001].) In this interpretation, private agents observe a signal $s_{t}$ given by

$$
s_{t}=\mu_{t}+\varepsilon_{t} .
$$

We think of $s_{t}$ as being the observed money growth rate (say, the growth rate of M3), and we think of $\mu_{t}$ as the collection of central bank monetary policy actions, such as open market operations, discount window operations, and quantitative restrictions on bank lending, all intended to move the observed money growth rate toward the rate actually intended. We think of $\varepsilon_{t}$ as a type of control error arising from shocks to the financial system. In the model here, we have $\pi_{t}=s_{t}$, so that inflation equals observed money growth. All of our results go through if we allow for shocks in the relationship between observed money growth and inflation, so that

$$
\pi_{t}=s_{t}+\nu_{t},
$$

where $\nu_{t}$ is an i.i.d. shock, thought of as a velocity shock. In this case, the tightness of money is the sum of the variances of the control error $\varepsilon_{t}$ and the velocity shock $\nu_{t}$.

Notice that we can interpret a transparent instrument in a similar way. For example, we can suppose that the signal of the policy is the exchange rate, the variance of the control error is zero, and the relation between the signal and inflation is subject to shocks. (Here, $s_{t}=e_{t}$, and $\pi_{t}=s_{t}+\pi_{t}^{*}$.)

\section{With Commitment: Only Tightness Matters}

We begin our analysis of tightness and transparency by considering a setup in which the central bank can commit to its policy. We establish that under such commitment, transparency is irrelevant for the choice of the optimal instrument; the relative desirability of an instrument depends only on its tightness. We then show that in such a setup, interest rates have a natural advantage over money growth rates as monetary policy instruments.

\section{II.A. Money $\mathcal{E}$ Exchange Rates}

We begin our analysis by considering policy instruments relevant for economies with poorly developed financial markets. Such economies cannot use interest rates as a monetary policy instrument, so we consider a version of our model without interest rates as an option. 
In this model, the idea behind commitment by the central bank is that at the beginning of period 0 , the central bank chooses rules governing its monetary policy in period $t$ as a function of the history of what it has observed up until that time and cannot deviate from them.

Within each period, the timing of actions is as follows. At the beginning of a period, private agents choose their nominal wages. The central bank then sets either an exchange rate regime or a money growth regime according to the rule chosen in period 0 . The choice of regime is observable. Finally, the central bank sets either the rate of change in the exchange rate or the rate of growth of the money supply.

We begin with the problem of the representative private agent in some period $t$. An agent's choice of the change in the agent's own wage rate, $z_{t}$, depends on whether the policy rule prescribes that the regime in the current period is an exchange rate regime or a money regime. We denote these choices by $z_{e t}$ and $z_{\mu t}$ and the corresponding average wage rates by $x_{e}$ and $x_{\mu}$. Clearly, given (5), under either regime, agents aim to choose wages equal to mean inflation, either $e$ or $\mu$, depending on the regime, so that

$$
z_{e t}=\int \pi_{t} g\left(\pi_{t} \mid e_{t}\right) d \pi=e_{t} \text { and } z_{\mu t}=\int \pi_{t} f\left(\pi_{t} \mid \mu_{t}\right) d \pi=\mu_{t}
$$

In what follows, we focus on equilibria that are symmetric; all agents choose the same individual wage rates, so that $x_{e t}=z_{e t}$ and $x_{\mu t}=z_{\mu t}$. Thus, all agents have the same utility. The central bank's expected payoffs are $S\left(x_{e t}, e_{t}\right)=\int r^{A}\left(x_{e t}, x_{e t}, \pi_{t}\right) g\left(\pi \mid e_{t}\right) d \pi$ and $R\left(x_{\mu t}, \mu_{t}\right)=$ $\int r^{A}\left(x_{\mu t}, x_{\mu t}, \pi_{t}\right) f\left(\pi \mid \mu_{t}\right) d \pi$ under the exchange rate and money regimes, respectively. With our functional forms, these become

$$
\begin{aligned}
& S\left(x_{t}, e_{t}\right)=-\frac{1}{2}\left[\left(e_{t}-x_{t}\right)^{2}+\left(e_{t}-x_{t}-\bar{y}\right)^{2}+e_{t}^{2}\right]-\frac{3}{2} \sigma_{\pi^{*}}^{2} \text { and } \\
& R\left(x_{t}, \mu_{t}\right)=-\frac{1}{2}\left[\left(\mu_{t}-x_{t}\right)^{2}+\left(\mu_{t}-x_{t}-\bar{y}\right)^{2}+\mu_{t}^{2}\right]-\frac{3}{2} \sigma_{\varepsilon}^{2} .
\end{aligned}
$$

Notice that the central bank's expected payoffs in the two regimes are symmetric with respect to the policy variables $e_{t}$ and $\mu_{t}$. In particular, the functions $S$ and $R$ differ only with respect to the uncontrollable variances $\sigma_{\pi^{*}}^{2}$ and $\sigma_{\varepsilon}^{2}$, which are constants.

Since (1)-(3) are all static, the central bank's problem reduces to a static one. If the central bank chooses the exchange rate regime, using (7) and $x_{e t}=z_{e t}$ in (8) gives that the central bank solves $\max _{e} S(e, e)$. If instead the central bank chooses the money regime, using 
(7) and $x_{\mu t}=z_{\mu t}$ in (9) gives that the central bank solves $\max _{\mu} R(\mu, \mu)$. The central bank then picks the regime with the higher utility. Given the symmetry of (8) and (9), we see that the preferred regime is the one with the lower variance of shocks. We then have

\section{Proposition 1. Only Tightness Matters with Commitment}

When the central bank can commit to its monetary policies, the tighter instrument is preferred regardless of its transparency. Thus, with commitment, the exchange rate regime is preferred to a money regime if and only if $\sigma_{\pi^{*}}^{2} \leq \sigma_{\varepsilon}^{2}$.

Here we have shown one sense in which transparency is irrelevant. A more general sense of irrelevance comes from comparing two environments, one in which, as above, money is opaque and exchange rates are transparent and another in which both instruments are transparent. Transparency is irrelevant if the optimal instrument is the same in both environments for all parameter values. Transparency is clearly irrelevant in this more general sense as well.

\section{II.B. Money $\&$ Interest Rates}

Now we consider a version of our model with money growth rates and interest rates instead of exchange rates. Developed countries do have interest rates as a monetary policy instrument, so this version of the model is more relevant for them. They, of course, could also choose another price, exchange rates, but we omit that option here for notational convenience.

We first define a precise notion of competitive equilibrium and argue that here also transparency is irrelevant under commitment.

We then consider the implications of the endogenous tightness of interest rates. We begin with a conventional way of modeling policies under commitment, referred to as restricted policies in which policies and allocations are linear rules that feed back on the history of events and actions. This way of modeling policies is standard in the macroeconomics literature. (See, for example, Woodford [2003].) We show that when such policies satisfy the Taylor principle, interest rate rules give rise to a unique equilibrium, and when they do not, equilibrium is indeterminate.

We then consider a notion of equilibrium in which policies and allocations are functions of past actions as well as exogenous shocks, referred to as an equilibrium with sophisticated 
policies. Note that this formulation allows policies to react to deviations by private agents. We show that any competitive equilibrium can be uniquely implemented with sophisticated policies. Interestingly, with sophisticated policies, the best interest rate policy violates the Taylor principle. Moreover, interest rate policies have a natural advantage over money growth policies in the sense that even if the interest rate shock $\eta_{t}$ has the same variance as the money growth shock $\varepsilon_{t}$, interest rate policies are strictly preferred.

In a version of the model that includes exchange rates, similar arguments would imply that when the interest rate shock has the same variance as the exchange rate shock $\pi_{t}^{*}$, interest rate policies are strictly preferred to exchange rate policies.

\section{II.B.1. Competitive Equilibrium}

First we describe the history of events and actions in our model with commitment and the outcomes under a competitive equilibrium. We see that here transparency is irrelevant in the choice of a monetary policy instrument.

The public events that occur in a period are, in chronological order, $q_{t}=\left(x_{t} ; \delta_{t}, i_{t} ; \eta_{t}, y_{t}, \pi_{t}\right)$, where $\delta_{t}=M$ denotes the money regime and $\delta_{t}=E$, the exchange rate regime. Letting $h_{t}$ denote the history of these events from period 0 up to and including period $t$, we have that $h_{t}=\left(h_{t-1}, q_{t}\right)$ for $t \geq 1$ and $h_{0}=q_{0}$. As a matter of notational convenience, we focus on perfect public equilibria in which the central bank's strategy is a function of only the public history.

The public history faced by private agents in period $t$ when they set their wages is $h_{t-1}$. The public history faced by the central bank (or government) when it sets its regime and either its money growth or interest rate policy is $h_{g t}=\left(h_{t-1}, x_{t}\right)$. A strategy for private agents is a sequence of rules $\sigma_{z}=\left\{z_{t}\left(h_{t-1}\right)\right\}$ for choosing wages for every possible public history, while average wages are given by $\sigma_{x}=\left\{x_{t}\left(h_{t-1}\right)\right\}$. A strategy for the central bank is a sequence of rules for choosing the regime, $\left\{\delta_{t}\left(h_{g t}\right)\right\}$ as well as the policy within the regime, either $\mu_{t}\left(h_{g t}\right)$ or $i_{t}\left(h_{g t}\right)$.

If the money regime is chosen in period $t\left(\delta_{t}\left(h_{g t}\right)=M\right)$, then interest rates $i_{t}\left(h_{y t}(M)\right)$ as well as output $y_{t}\left(h_{y t}(M)\right)$ and inflation rates $\pi_{t}\left(h_{y t}(M)\right)$ are determined residually from (1)-(4) after the relevant shocks are realized, where $h_{y t}(M)=\left(h_{t-1}, x_{t} ; M, \mu_{t} ; \eta_{t}, \varepsilon_{t}\right)$ is the history that determines output, inflation, and interest rates in the current period.

If, instead, in period $t$ the interest rate regime is chosen $\left(\delta_{t}\left(h_{g t}\right)=I\right)$, then the money 
growth rate $\mu_{t}\left(h_{y t}(I)\right)$ as well as output $y_{t}\left(h_{y t}(I)\right)$ and inflation $\pi_{t}\left(h_{y t}(I)\right)$ are determined residually from (1)-(4) after the relevant shocks are realized, where $h_{y t}(I)=\left(h_{t-1}, x_{t} ; I, i_{t} ; \eta_{t}, \varepsilon_{t}\right)$ is the history that determines output, inflation, and money growth in the current period.

We let $\sigma_{g}$ denote the regime choice and the policies under that regime. At the end of period $t$, output and inflation are determined as functions of the relevant history of the game $h_{y t}\left(\delta_{t}\right)$ according to the rules $y_{t}\left(h_{y t}\left(\delta_{t}\right)\right)$ and $\pi_{t}\left(h_{y t}\left(\delta_{t}\right)\right)$. We let $\sigma_{y}=\left\{y_{t}\left(h_{y t}\left(\delta_{t}\right)\right)\right\}$ and $\sigma_{\pi}=\left\{\pi_{t}\left(h_{y t}\left(\delta_{t}\right)\right)\right\}$ denote the sequences of output and inflation rules.

In any equilibrium, the representative agent's wage equals that agent's expectation of inflation. We write this condition as

$$
z_{t}\left(h_{t-1}\right)=E\left[\pi_{t} \mid h_{t-1}\right] .
$$

In (10), given $h_{t-1}$ agents use the average wage rule $x_{t}\left(h_{t-1}\right)$, the central bank's strategies, and the distribution of exogenous shocks to forecast the distribution of inflation.

A competitive equilibrium given the policies here is a collection of strategies $\left(\sigma_{g}, \sigma_{z}, \sigma_{x}\right)$ and output and inflation rules $\left(\sigma_{y}, \sigma_{\pi}\right)$ such that, given $\sigma_{g}$ and $\sigma_{x}, \sigma_{z}$ is optimal, in that for all histories, the average wage equals the representative agent's wage

$$
x_{t}\left(h_{t-1}\right)=z_{t}\left(h_{t-1}\right)
$$

and the output rule, the inflation rule, and the residually determined policy choice satisfy (1)-(3). In light of condition (11) and the observation that given $\left(\sigma_{g}, \sigma_{x}\right)$, output, inflation, and the residually determined policy choice are mechanically given by (1)-(3), we summarize a competitive equilibrium by $\left(\sigma_{g}, \sigma_{x}\right)$. Note for later, from (10) and (11), that

$$
x_{t}\left(h_{t-1}\right)=E\left[\pi_{t} \mid h_{t-1}\right] .
$$

Associated with each competitive equilibrium $\sigma=\left(\sigma_{g}, \sigma_{x}\right)$ are the particular stochastic processes for outcomes that occur along the equilibrium path. These outcomes can be generated from the strategies in the standard recursive fashion. Clearly, these outcomes can be written as a function of the history of exogenous events $s^{t}=\left(s_{0}, \ldots, s_{t}\right)$, where $s_{t}=\left(\varepsilon_{t}, \eta_{t}\right)$. These (on the equilibrium path) outcomes include allocations $a(\sigma)=\left\{x_{t}\left(s^{t-1} ; \sigma\right), \pi_{t}\left(s^{t} ; \sigma\right), y_{t}\left(s^{t} ; \sigma\right)\right\}$. We call an allocation $a(\sigma)$ associated with a competitive equilibrium $\sigma$ a competitive allocation. 
Later, we often suppress explicit dependence on $\sigma$. We also let $a$ denote allocations of the form $\left\{x_{t}\left(s^{t-1}\right), \pi_{t}\left(s^{t}\right), y_{t}\left(s^{t}\right)\right\}$.

We define a Ramsey allocation to be the allocation $a$ associated with a competitive equilibrium $\sigma$ that maximizes the central bank's payoff in period 0 over the set of all competitive allocations.

Clearly, in the model described here, transparency is irrelevant in the more general sense described above. Regardless of whether money growth is observed or not, the central bank commits to a policy rule in period 0 and over time, and deviations from that rule are simply prohibited. Hence, the central bank has no incentive constraints for which the lack of observability of its action may be relevant. The analog of Proposition 1 thus holds.

We now turn to characterizing the set of equilibrium outcomes. We begin with a simple lemma. The lemma shows that under any interest rate rule, the expected inflation rate is uniquely determined by the policy, but the realized inflation rate may not be.

Lemma. In any history $h_{t-1}$,

$$
E\left[y_{t} \mid h_{t-1}\right]=0
$$

If that history gives rise to an interest rate regime, then

$$
E\left[\pi_{t+1} \mid h_{t-1}\right]=i_{t}\left(h_{g t}\right),
$$

where $h_{g t}=\left(h_{t-1}, x_{t}\left(h_{t-1}\right)\right)$.

Proof. Taking expectations of the Phillips curve equation (1) with respect to $h_{t-1}$ gives

$$
E\left[y_{t} \mid h_{t-1}\right]=E\left[\pi_{t} \mid h_{t-1}\right]-x_{t}\left(h_{t-1}\right)
$$

Using (12), we then have that $E\left[y_{t} \mid h_{t-1}\right]=0$ for all $t$, which proves (13).

Taking expectations of the Euler equation (4) with respect to $h_{t-1}$ gives

$$
E\left[y_{t} \mid h_{t-1}\right]=E\left[y_{t+1} \mid h_{t-1}\right]-\sigma\left(i_{t}\left(h_{t-1}\right)-E\left[\pi_{t+1} \mid h_{t-1}\right]\right)
$$

Using the law of iterated expectations gives that $E\left[y_{t+1} \mid h_{t-1}\right]=0$. From (15) we then have (14), that $E\left[\pi_{t+1} \mid h_{t-1}\right]=i_{t}\left(h_{g t}\right)$. Q.E.D. 


\section{II.B.2. Equilibrium with Restricted Policies}

The standard way to model policies under commitment is to restrict policies and allocations to linear feedback rules (that agree on and off the equilibrium path). We show here that with such restricted policies, a model like ours produces the standard result: interest rate policies produce a unique equilibrium only when the policies satisfy the Taylor principle.

Policies of the Taylor rule form are given by

$$
i_{t}=\bar{\imath}+a E_{t-1} \pi_{t}+b E_{t-1} y_{t}
$$

where $\bar{l}$ is a constant. When the parameter $a>1$, such policies are said to satisfy the Taylor principle, namely, that the central bank should raise its interest rate more than one-for-one with increases in inflation. When $a<1$, such policies are said to violate that principle.

Of course, the Taylor rule is not a well-defined function of histories until we fill in how expectations are formed. From the lemma, we know that $E\left[y_{t} \mid h_{t-1}\right]=0$. Since $E\left[\pi_{t} \mid h_{t-1}\right]=x_{t}$, policies of the Taylor rule form can be written as

$$
i_{t}=\bar{\imath}+a x_{t}
$$

We follow the literature in focusing on equilibria in which all outcomes are linear functions of the history. As is well-known, in economies like ours, if the Taylor principle is violated, a large number of such equilibria are associated with a given restricted policy, while if the principle is

satisfied, a unique bounded linear equilibrium is associated with the policy. Formally, here we have

\section{Proposition 2. Determinacy of Equilibrium and the Taylor Principle}

The linear equilibria with interest rate rules of the Taylor rule form (17) have outcomes of the form

$$
x_{t+1}=i_{t}+c \eta_{t}, \quad \pi_{t}=x_{t}+(1+\sigma c) \eta_{t}, \quad \text { and } y_{t}=(1+\sigma c) \eta_{t}
$$

For every $a<1$ and $\bar{\imath}$, the economy has a continuum of equilibria indexed by the parameter c. For every $a \geq 1$ and $\bar{\imath}$, within the class of bounded linear equilibria, the economy has a unique equilibrium with $c=0$. 
Proof. From the lemma, we know that $E\left[\pi_{t+1} \mid h_{t-1}\right]=i_{t}\left(h_{g t}\right)$. From the form of the Taylor rule (16), we know that $E\left[\pi_{t+1} \mid h_{t-1}\right]=\bar{\imath}+a x_{t}$; from (12) and linearity, we then have that all linear equilibria must satisfy (18). If $a<1$, verifying that the outcomes for $\pi_{t}$ and $y_{t}$ are equilibria for any value of $c$ follows from verifying the equilibrium conditions. If $a>1$, clearly any nonzero value of $c$ implies that $x_{t}$ is unbounded.

Q.E.D.

The intuitive idea behind the multiplicity of equilibria in Proposition 2 is that interest rates pin down only expected inflation and not the state-by-state realizations indexed by the parameter $c$.

Here we have focused on linear Taylor rules. Now consider more general rules of the form $i_{t}=f\left(x_{t}\right)$, where $f$ is a smooth function. Suppose that a steady-state equilibrium exists with $x_{t}=x_{s s}$. It is straightforward to adapt standard arguments to show the following. If $f^{\prime}\left(x_{s s}\right)<1$, then the economy has a continuum of equilibria converging to $x_{s s}$. If $f^{\prime}\left(x_{s s}\right)>1$, then the equilibria are locally determinate and coincide with the linear equilibria that satisfy the Taylor principle.

Interestingly, it turns out that equilibria that satisfy the Taylor principle are inefficient in that they are dominated by an equilibrium that violates that principle. Consider the best equilibrium outcomes in the class considered in Proposition 2. Clearly, the optimal average inflation rate is zero. From the lemma, this outcome is accomplished by setting $i_{t}=0$ for all $t$ and, hence, $\bar{\imath}=a=0$. Given the form of the objective function in (6), the best equilibrium then minimizes the sum of the variances of inflation and output. From the form of the equilibrium in Proposition 2, the variance of inflation is $(1+\sigma c)^{2} \sigma_{\eta}^{2}+c^{2} \sigma_{\eta}^{2}$, and that of output is $(1+\sigma c)^{2} \sigma_{\eta}^{2}$.

Notice that starting at $c=0$, a small decrease in $c$ reduces the variance of both inflation and output and thus raises welfare. More generally, the value of $c$ that maximizes welfare is

$$
c=-2 \sigma /\left(1+2 \sigma^{2}\right) \text {. }
$$

We summarize this discussion with a proposition.

\section{Proposition 3. Rules Satisfying the Taylor Principle Are Inefficient}

The outcomes under a Taylor rule of the form (17) with $a>1$ are dominated by the outcomes of an equilibrium with $a=0$ and $\bar{\imath}=0$. 
To get some intuition for this proposition, think of $\eta_{t}$ as a type of demand shock, a shock that distorts the intertemporal marginal rate of substitution. When $\eta_{t}$ is positive, the Euler equation (4) implies that for a given value of expected consumption and real interest rates, desired consumption at $t$ rises. In a determinate equilibrium, $c=0$. Hence, when desired consumption at $t$ rises, actual consumption rises one-for-one. For the economy to produce this increased output, the Phillips curve (1) implies that (unexpected) inflation must rise one-forone as well. The opposite happens when the shock to marginal utility is negative. Hence, in this economy, output and inflation simply inherit the variability of the demand shock.

Now consider an equilibrium of the sort considered in Proposition 2 with $c$ negative. In this equilibrium, when the demand shock is positive, real interest rates in (4) rise because expected inflation rises. This rise in real interest rates dampens the rise in desired consumption. Actual consumption then rises less than one-for-one with the shock, and from the Phillips curve we know that inflation does too. Thus, the variability of output and that of inflation are lower in this equilibrium than in a determinate equilibrium.

We have shown that in the best equilibrium $\bar{\imath}=0, a=0$, and $c<0$. The problem, however, is that this equilibrium lies in the indeterminate region. If a central bank follows a policy of setting $a=0$, the best outcome may be realized. However, any of a continuum of worse outcomes could also be realized. This possibility makes following a policy of setting $\bar{\imath}=0$ risky relative to one that satisfies the Taylor principle.

In the next section, we argue that the indeterminacy of equilibria in this economy is entirely an artifact of the restrictions placed on policies and that once these restrictions are removed, the best equilibrium can be uniquely implemented.

\section{II.B.3. Equilibrium with Sophisticated Policies}

Here we show that by allowing central bank behavior after deviations by private agents to be different from central bank behavior when agents do not deviate, we can implement any outcome path associated with restricted policies as a unique equilibrium, including those that violate the Taylor principle. The indeterminacy of equilibrium with $a<1$ arises because restricted policies specify the same policy rule both on and off the equilibrium path; that is, they specify the same rule for all histories of choices, including deviations by private agents. (Since we are considering environments with commitment, deviations by the central bank are 
irrelevant.) We call policies that are not so restricted sophisticated policies.

Suppose that interest rates are the chosen policy instrument. Fix a desired outcome path $\left(\hat{x}_{t}\left(s^{t-1}\right), \hat{\pi}_{t}\left(s^{t}\right), \hat{y}_{t}\left(s^{t}\right)\right)$ together with central bank policies $\hat{\imath}_{t}\left(s^{t-1}\right)$. Consider the following trigger-type policy that supports these outcomes as unique equilibria: If the history of private actions coincides with the desired outcomes, then let central bank policy in period $t$ be $\hat{\imath}_{t}\left(s^{t-1}\right)$. If the history up until period $t-1$ coincides with the desired outcomes, but the wage rate chosen by private agents $x_{t} \neq \hat{x}_{t}\left(s^{t-1}\right)$, then in period $t$ and thereafter switch to a money regime with money growth in a given period equal to the expected value of inflation for that period in the original equilibrium. That is, in period $r \geq t$, set $\mu_{r}\left(s^{r-1}\right)=\hat{x}_{r}\left(s^{r-1}\right)$.

Clearly, under such a policy, for a private agent the expected inflation rate is $\hat{x}_{t}\left(s^{t-1}\right)$ regardless of the behavior of other private agents. Hence, each private agent sets $z_{t}\left(s^{t-1}\right)=$ $\hat{x}_{t}\left(s^{t-1}\right)$. Thus, the equilibrium is unique.

We summarize this discussion with a proposition:

\section{Proposition 4. Unique Equilibrium with Sophisticated Policies}

Any competitive equilibrium outcome can be implemented as a unique equilibrium with sophisticated policies.

In proving Proposition 4, we have assumed that after a deviation by private agents, the central bank switches to a money regime. Alternatively, we could have used the following trigger-type policy in which the central bank stays in an interest rate regime both on and off the equilibrium path. We support a desired outcome path $\left(\hat{x}_{t}\left(s^{t-1}\right), \hat{\pi}_{t}\left(s^{t}\right), \hat{y}_{t}\left(s^{t}\right)\right)$ together with central bank policies $i_{t}^{*}\left(s^{t-1}\right)$ as a unique equilibrium as follows. If the history of private actions coincides with the desired outcomes, then let central bank policy in period $t$ be $\hat{\imath}_{t}\left(s^{t-1}\right)$. If the history up until period $t-1$ coincides with the desired outcomes, but the wage rate chosen by private agents $x_{t} \neq x_{t}\left(s^{t-1}\right)$, then in period $t$ and thereafter switch to a policy rule that satisfies the Taylor principle but has the same expected inflation as the original outcome path. This strategy will lead to a unique equilibrium.

Note that since outcomes with restricted and sophisticated policies coincide along the equilibrium path, data from the equilibrium of the model cannot be used to determine whether restricted or sophisticated policies are being followed. 
We turn now to the optimal choice of a monetary policy instrument under commitment when sophisticated policies are allowed. The optimal money growth policy has $\mu_{t}=0$ in all periods. This leads to zero inflation on average, and the resulting variance of both inflation and output is $\sigma_{\varepsilon}^{2}$. To see if interest rates have a natural advantage over money growth rates, we begin by considering a suboptimal interest rate policy that sets the interest rate $i_{t}=0$ along the equilibrium path and implements an equilibrium of the form of Proposition 2 with $c=0$. This policy leads to zero inflation on average, and the resulting variance of both inflation and output is $\sigma_{\varepsilon}^{2}$. If $\sigma_{\varepsilon}^{2}=\sigma_{\eta}^{2}$, then welfare under this suboptimal interest rate policy is equal to welfare under the best money growth policy. Hence, welfare is strictly greater under the optimal interest rate policy than under the optimal money growth policy. We then have the following proposition:

\footnotetext{
Proposition 5. The Natural Advantage of Interest Rates

If $\sigma_{\varepsilon}^{2}=\sigma_{\eta}^{2}$, then interest rates are strictly preferred to money growth rates as a policy instrument.
}

In sum, we have shown that with sophisticated policies, interest rate policies need not lead to indeterminacy. We have noted that in terms of observed outcomes, those under restricted policies coincide with those under sophisticated policies. Finally, we have also shown that because the tightness of interest rates is endogenous, policy can be chosen so as to make interest rates tighter than the variance of the interest shock $\eta_{t}$.

\section{Without Commitment: Transparency Matters Too}

In our model this lack of commitment leads to a time inconsistency problem. Now we consider a setup in which the central bank cannot commit to its policies. We show that in this setup, both tightness and transparency matter, and a transparent instrument has a natural advantage over an opaque one. For notational convenience, we focus on an economy with just money and exchange rates. (The analysis with money and interest rates is similar.)

We model the lack of commitment by assuming the following timing of actions within each period. We suppose that the central bank cannot commit to its policies. In each period, agents 
set their wages, and then the central bank chooses the regime and the level of its monetary policy instrument. For this environment, we show that transparency is a desirable feature for an instrument. Specifically, we show that if the exchange rate and the money growth rate are equally tight instruments, then given any equilibrium in which the central bank chooses a money regime in some period $t$, we can construct another equilibrium in which the central bank chooses instead an exchange rate regime in period $t$ and obtains a strictly higher payoff. Thus, even if money growth is the tighter instrument, an exchange rate regime is preferred because of its transparency. We say, therefore, that the exchange rate's greater transparency gives it a natural advantage as a monetary policy instrument.

\section{III.A. Strategies \& Constraints}

A perfect equilibrium in this environment is a collection of strategies $\sigma$ such that $(i)$ after every history $h_{t-1}$, the private agents' strategy $\sigma_{z}$ is optimal given the central bank's strategy $\sigma_{g}$ and the average of agents' wages $\sigma_{x} ;(i i)$ after every history $h_{g t}$, the central bank's strategy $\delta_{t}\left(h_{g t}\right)$ and the relevant policy choice, either $e_{t}\left(h_{g t}\right)$ or $\mu_{t}\left(h_{g t}\right)$, are optimal given the average of agents' wages $\sigma_{x}$; and (iii) after every history $h_{t-1}, \sigma_{z}$ and $\sigma_{x}$ agree.

In this analysis, we will formulate the incentive constraint of the central bank recursively, by drawing on the work of Abreu, Pearce, and Stacchetti [1986, 1990]. Their basic idea applied to our model comes from a simple insight. It starts with the recognition that in order to evaluate the central bank's incentive constraints, we need not specify the whole sequence of future actions for the central bank and private agents that follow every possible current action that the central bank might take. Rather, all we need specify is how the central bank's payoff from the next period on - its continuation value - will vary as the central bank's current action varies. This simple observation forms the basis for a recursive approach to describing the incentive compatibility constraints for the central bank.

To formulate the incentive constraint of the central bank recursively, we use the fact that strategies induce continuation values in a natural way. Fix a collection of strategies $\sigma=\left(\sigma_{g}, \sigma_{x}\right)$. For any history, these strategies imply a stochastic outcome path and an associated expected discounted value of utility, referred to as a continuation value. Suppose that, in period $t$

following history $h_{g t}$, the central bank has chosen a money regime $\left(\delta_{t}\left(h_{g t}\right)=M\right)$ and private agents have chosen a wage $x_{t}$. Since agents observe only inflation $\pi_{t}=\mu_{t}+\varepsilon_{t}$, which is a noisy 
signal of $\mu_{t}$, the equilibrium following period $t$ as specified in a collection of strategies $\sigma$ cannot depend on the central bank's choice of $\mu_{t}$ directly; it can vary only with inflation $\pi_{t}$. Hence, the central bank's continuation value from next period can depend only on $\pi_{t}$ and $h_{g t}$. (Note that it is redundant to have these strategies vary with $y_{t}$ as well.) Denote the continuation value function under a money regime by $w_{\mu t+1}\left(\pi_{t}, h_{g t}\right)$. Likewise, denote the continuation value function under an exchange rate regime by $w_{\text {et+1 }}\left(e_{t}, h_{g t}\right)$.

In each period, the central bank has two types of incentive constraints, one for the choice of regime and one for the choice of policy within each regime. Working backward, consider first the incentive constraint for money growth in the money regime in period $t$. Suppose that the strategy $\sigma_{g}$ specifies that the central bank choose $\mu_{t}\left(h_{g t}\right)$ in the current period. Given the current wage chosen by the agents $x_{t}$ and the continuation value function $w_{\mu t+1}\left(\pi_{t}, h_{t}\right)$, the incentive constraint requires that there be no other money growth rate, $\mu_{t}^{\prime} \neq \mu_{t}\left(h_{g t}\right)$, such that the central bank could benefit by deviating to $\mu_{t}^{\prime}$ in period $t$ and then acting according to its strategy $\sigma_{g}$ from period $t+1$ on; that is,

$$
\begin{aligned}
& (1-\beta) R\left(x_{t}, \mu_{t}\left(h_{g t}\right)\right)+\beta \int w_{\mu t+1}\left(\pi, h_{t}\right) f\left(\pi \mid \mu_{t}\left(h_{g t}\right)\right) d \pi \geq \\
& (1-\beta) R\left(x_{t}, \mu_{t}^{\prime}\right)+\beta \int w_{\mu t+1}\left(\pi, h_{t}\right) f\left(\pi \mid \mu_{t}^{\prime}\right) d \pi
\end{aligned}
$$

for any possible $\mu_{t}^{\prime}$ and for all $h_{g t}$. (Recall that $R$ and $S$ represent the central bank's expected payoffs under a money regime and an exchange rate regime, respectively.) Notice that here a deviation $\mu_{t}^{\prime}$ from the specified current action $\mu_{t}\left(h_{g t}\right)$ affects the central bank's expected discounted payoff only by shifting the distribution of inflation from $f\left(\pi \mid \mu_{t}\left(h_{g t}\right)\right)$ to $f\left(\pi \mid \mu_{t}^{\prime}\right)$.

Consider next the incentive constraint for the exchange rate in the exchange rate regime in period $t$. Given the wage $x_{t}$ chosen by agents, this incentive constraint is

$$
(1-\beta) S\left(x_{t}, e_{t}\left(h_{g t}\right)\right)+\beta w_{e t}\left(e_{t}\left(h_{g t}\right), h_{t-1}\right) \geq(1-\beta) S\left(x_{t}, e_{t}^{\prime}\right)+\beta w_{e t}\left(e_{t}^{\prime}, h_{t-1}\right)
$$

for any possible $e_{t}^{\prime}$ and $h_{g t}$.

Finally, consider the incentive constraint for the choice of regime. In period $t$, after history $h_{g t}$, the money regime is optimal, $\delta_{t}\left(h_{g t}\right)=M$, only if

$$
(1-\beta) R\left(x_{t}, \mu_{t}\left(h_{g t}\right)\right)+\beta \int w_{\mu t+1}\left(\pi, h_{t}\right) f\left(\pi \mid \mu_{t}\left(h_{g t}\right)\right) d \pi \geq
$$




$$
\max _{e_{t}}(1-\beta) S\left(x_{t}, e_{t}\right)+\beta w_{e t+1}\left(e_{t}, h_{t}\right) .
$$

Likewise, the exchange rate regime is optimal, $\delta_{t}\left(h_{g t}\right)=E$, if an analogous constraint holds.

Notice that in (20), (21), and (22) we are only considering one-shot deviations, that is, changes in the current actions, holding fixed the future strategies. A standard result in game theory says that since the payoffs of the central bank are bounded, these recursive incentive constraints are both necessary and sufficient for full incentive compatibility.

\section{III.B. Transparency's Advantage}

The following proposition establishes the precise advantage of the transparent instrument when the central bank cannot commit to its policies.

\section{Proposition 6. The Advantage of Transparency}

When two monetary policy instruments have equal tightness and the central bank cannot commit to its monetary policies, the transparent instrument is preferred to the opaque instrument in the following sense: For any equilibrium $\sigma$ in which the money regime is chosen in at least one period, there is an equilibrium $\tilde{\sigma}$ with higher welfare in which the exchange rate regime is chosen in all periods.

The idea of the proof of this proposition is the following. To achieve a good outcome, the continuation payoff must have two features simultaneously. It must deter the central bank from deviating from the prescribed policy, and it must give the central bank a high continuation payoff when the central bank does not deviate.

With a transparent instrument, any deviation is perfectly detectable, and these two features do not conflict. The continuation payoff function can specify the lowest possible continuation when there is any deviation and the highest possible continuation when there is none.

With an opaque instrument, however, the continuation payoff function can depend only on a noisy signal of the policy, so these features do conflict. If the continuation payoff function specifies the highest payoff regardless of the observed noisy signal, then the payoff has no deterrence value and results in the one-shot equilibrium outcome. If this function builds in any deterrence value by prescribing lower continuation values for some inflation rates, then 
with positive probability the lower continuation value must be realized even if the central bank pursues the desired policy. This feature necessarily leads to lower payoffs along the equilibrium path. In this sense, the advantage of transparency arises from the ability to precisely tailor the continuation payoff function to deviations: it can give high payoffs only when exactly the right policy is being pursued, and it can give low payoffs when any other policy is used.

In the formal proof, we use the static Nash equilibrium in money growth rates. For that equilibrium, we let $\left(x_{N}, \mu_{N}\right)$ be such that $\mu_{N}=\arg \max _{\mu} R\left(x_{N}, \mu\right)$ and $x_{N}=\mu$. (For our model, it is easy to show that $x_{N}=\bar{y}$.)

Proof of Proposition 6. Let $\sigma$ be equilibrium strategies in which the money regime is chosen somewhere along the equilibrium path. Let $t$ be the first period in which a money regime is chosen. Let $h_{g t}$ be the history of central bank actions along the equilibrium path before period $t$ for the particular history, with agents' wage $x_{t}$, a money growth rate $\mu_{t}\left(h_{g t}\right)$, and the continuation value $w_{\mu t+1}\left(\pi, h_{t}\right)$.

Suppose first that the money growth rate $\mu_{t}\left(h_{g t}\right)$ is strictly less than the static Nash money growth rate $\mu_{N}$. Then necessarily the continuation values $w_{\mu t+1}\left(\pi, h_{g t}\right)$ must depend nontrivially on $\pi$. (Otherwise, the central bank would deviate.) Let $\bar{w}_{t+1}\left(h_{g t}\right)$ and $\underline{w}_{t+1}\left(h_{g t}\right)$ denote the highest and the lowest continuation values after $h_{t}$ under the equilibrium $\sigma$, so that $\bar{w}_{t+1}\left(h_{g t}\right)=\max _{\pi} w_{\mu t+1}\left(\pi, h_{g t}\right)$ and $\underline{w}_{t+1}\left(h_{g t}\right)=\min _{\pi} w_{\mu t+1}\left(\pi, h_{g t}\right)$, where, because the continuation values depend nontrivially on $\pi, \bar{w}_{t+1}\left(h_{g t}\right)>\underline{w}_{t+1}\left(h_{g t}\right)$.

We construct the better equilibrium $\tilde{\sigma}$ - that is, one with higher welfare than $\sigma$-as follows. In period $t$, after history $h_{g t}$, let $\tilde{\sigma}$ specify that the exchange rate regime is chosen, and let the exchange rate be chosen to produce the same mean inflation rate as under the original equilibrium $\sigma$; that is, let $\tilde{e}_{t}\left(h_{g t}\right)=\mu_{t}\left(h_{g t}\right)$ be the exchange rate. Let the central bank's continuation value be

$$
\tilde{w}_{e t+1}\left(e_{t}, h_{g t}\right)=\left\{\begin{array}{l}
\bar{w}_{t+1}\left(h_{g t}\right) \text { if } e_{t}=\tilde{e}_{t}\left(h_{g t}\right) \\
\underline{w}_{t+1}\left(h_{g t}\right) \text { if } e_{t} \neq \tilde{e}_{t}\left(h_{g t}\right)
\end{array}\right\} .
$$

In the original equilibrium $\sigma$, the continuation values $\bar{w}_{t+1}\left(h_{g t}\right)$ and $\underline{w}_{t+1}\left(h_{g t}\right)$ were supported by some particular strategies. In the equilibrium $\tilde{\sigma}$, let these continuation values be supported by the same strategies. Let agents' wage be $\tilde{x}_{t}\left(h_{t-1}\right)=\tilde{e}_{t}\left(h_{g t}\right)=\mu_{t}\left(h_{g t}\right)$. For all other histories not specified so far, let $\tilde{\sigma}$ coincide with $\sigma$. 
Clearly, to show that our constructed strategies are an equilibrium, we need to show that they satisfy the incentive constraint for the central bank after $h_{g t}$ when the exchange rate regime is chosen. We also need to show that incentive constraints in prior periods are satisfied.

To see that the incentive constraint in period $t$ is satisfied, note that in the original equilibrium, the incentive constraint can be written as

$$
(1-\beta)\left[R\left(x_{t}, \mu_{t}^{\prime}\right)-R\left(x_{t}, \mu_{t}\left(h_{g t}\right)\right)\right] \leq \beta \int w_{\mu t+1}\left(\pi, h_{g t}\right)\left[f\left(\pi \mid \mu_{t}\left(h_{g t}\right)\right)-f\left(\pi \mid \mu_{t}\right)\right] d \pi
$$

where $x_{t}=x_{t}\left(h_{t-1}\right)$. Note that because $\bar{w}_{t+1}\left(h_{g t}\right)$ and $\underline{w}_{t+1}\left(h_{g t}\right)$ are the upper and lower bounds of the continuation value $w_{\mu t+1}\left(\pi, h_{g t}\right)$, the right side of (23) satisfies

$$
\int w_{\mu t+1}\left(\pi, h_{g t}\right)\left[f\left(\pi \mid \mu_{t}\left(h_{g t}\right)\right)-f\left(\pi \mid \mu_{t}\right)\right] d \pi<\bar{w}_{t+1}\left(h_{g t}\right)-\underline{w}_{t+1}\left(h_{g t}\right) .
$$

Next we show that the left side of (23) equals

$$
(1-\beta)\left[S\left(\tilde{x}_{t}\left(h_{t-1}\right), e_{t}^{\prime}\right)-S\left(\tilde{x}_{t}\left(h_{t-1}\right), \tilde{e}_{t}\left(h_{g t}\right)\right)\right] .
$$

This result holds because the two instruments are equally tight, the functions $S$ and $R$ coincide, and, by construction, the inherited wages in the better equilibrium equal those in the original equilibrium, $\tilde{x}_{t}\left(h_{t-1}\right)=x_{t}\left(h_{t-1}\right)$. Combining (23)-(25) gives

$$
(1-\beta)\left[S\left(\tilde{x}_{t}\left(h_{t-1}\right), e_{t}^{\prime}\right)-S\left(\tilde{x}_{t}\left(h_{t-1}\right), \tilde{e}_{t}\left(h_{g t}\right)\right)\right]<\beta\left[\bar{w}_{t}\left(h_{g t}\right)-\underline{w}_{t}\left(h_{g t}\right)\right]
$$

Since (23) holds for any deviation $\mu_{t}^{\prime}$, (26) holds for any deviation $e_{t}^{\prime}$.

Along the equilibrium path, the payoffs under our constructed strategies $\tilde{\sigma}$ - the left side of (21) - are strictly higher than those under $\sigma$ - the left side of (20) - since

$$
w_{e t}\left(\tilde{e}_{t}\left(h_{t}\right), h_{g t}\right)=\bar{w}_{t}\left(h_{g t}\right)>\int w_{\mu t}\left(\pi, h_{g t}\right) f\left(\pi \mid \mu_{t}\left(h_{g t}\right)\right) d \pi
$$

Hence, at the history $h_{t-1}$ under $\tilde{\sigma}$ the central bank strictly prefers to adopt the exchange rate regime, and welfare under $\tilde{\sigma}$ is strictly greater than under $\sigma$.

To see that the incentive constraints are satisfied in periods before $t$, note that by our definition of period $t$, in all prior periods the central bank's equilibrium strategy specified an exchange rate regime. Consider the incentive constraint in period $t-1$ under the original equilibrium $\sigma$ :

$$
(1-\beta) S\left(x_{t-1}, e_{t-1}\right)+\beta w_{e t-1}\left(e_{t-1}, h_{g t-1}\right) \geq(1-\beta) S\left(x_{t-1}, e_{t-1}^{\prime}\right)+\beta w_{e t-1}\left(e_{t-1}^{\prime}, h_{g t-1}\right)
$$


for all $e_{t-1}^{\prime}$, where $e_{t-1}=e_{t-1}\left(h_{g t-1}\right)$. By switching to $\tilde{\sigma}$, the left side of $(28)$ is increased while the right side is unaffected because $\tilde{\sigma}$ specifies the same continuation as $\sigma$ following any deviation. A similar argument applies to all preceding periods.

Now suppose that the money growth rate $\mu_{t}\left(h_{g t}\right)$ is not less than but rather equal to the static Nash money growth rate. Then, for any $\beta>0$, it is easy to show that an exchange rate $e_{t}$ strictly less than the $\mu_{t}\left(h_{g t}\right)$ can be supported. This variation also improves welfare.

Therefore, $\tilde{\sigma}$ is an equilibrium and, as we have shown, $\tilde{\sigma}$ has higher welfare than $\sigma$.

So far we have shown that given any equilibrium in which the money growth rate is used as an instrument in some period, there is an equilibrium in which the exchange rate is used as an instrument in that same period which leads to higher welfare. To do so, we constructed an alternative equilibrium in which we replaced a money regime by an exchange rate regime in the first period in which a money regime was chosen in the original equilibrium. Proceeding recursively, it is clear that the best equilibrium must have an exchange rate regime in all periods.

Q.E.D.

\section{III.C. Implications}

Proposition 6 implies that without commitment, both tightness and transparency are relevant for the optimal choice of a monetary policy instrument. In the best equilibrium without commitment, if money and exchange rates have equal tightness, then exchange rates are strictly preferred. By continuity, if money is a bit tighter than exchange rates, then exchange rates are still strictly preferred. Of course, if money is sufficiently tight, then it will be preferred to exchange rates.

In proving our result, we have imposed no restrictions on strategies besides the natural ones that arise from the environment. If we restrict strategies in the same way in both regimes, say, to Markov strategies (as does Stokey [2003]) or to strategies that allow only reversion to the one-shot equilibrium (as does Canzoneri [1985]), then we obtain similar results when we compare the best equilibria within these restricted classes. The logic is identical to that for our main result for an environment with no such restrictions.

In interpreting Proposition 6, note that we are ranking different equilibria. The model has many equilibria, and in any given one, the central bank is choosing its regime optimally, taking as given the behavior of private agents. We have left unspecified the mechanism by 
which any particular equilibrium is implemented. Rather, we have simply shown that in the best equilibrium, the more transparent instrument, the exchange rate, is chosen when both instruments are equally tight. Only in this particular sense have we shown that exchange rates have an advantage over money growth rates as a monetary policy instrument.

\section{Extensions}

Thus far we have assumed that intended money growth is never observable. Here we show that our results hold, with and without commitment, even when agents see other signals of intended money growth or when they see intended money growth after a lag.

\section{IV.A. A More General Setup}

Our setup with money and exchange rates is a special case of the following more general setup. The central bank chooses a regime $j \in\{M, E\}$ and an action $a_{j t}$ in regime $j$ in period $t$. Private agents see a signal $s_{j t}$ of this action

$$
s_{j t}=a_{j t}+\nu_{j t},
$$

where $\nu_{j t}$ is an i.i.d. control error with variance $\sigma_{\nu j}^{2}$. Inflation is determined according to

$$
\pi_{t}=s_{j t}+\omega_{j t}
$$

where $\omega_{j t}$ is an i.i.d. linkage error with variance $\sigma_{\omega j}^{2}$ that reflects the imperfect relationship between the signal and the outcome. The setup we have been using above is a special case of (29) and (30):

$$
\pi_{t}=a_{j t}+\nu_{j t}+\omega_{j t}
$$

In the money regime, the variance of the control error $\sigma_{\nu M}^{2}\left(=\sigma_{\varepsilon}^{2}\right)$ is positive, but the variance of the linkage error $\sigma_{\omega M}^{2}$ is zero. In the exchange rate regime, the reverse is true: the variance of the control error $\sigma_{\nu E}^{2}$ is zero, but the variance of the linkage error $\sigma_{\omega E}^{2}\left(=\sigma_{\pi^{*}}^{2}\right)$ is positive.

In the money regime, we think of the signal $s_{M t}$ as a monetary aggregate, say, M3, that the public perfectly observes. This monetary aggregate is determined in part by the actions 
of the central bank $a_{M t}=\mu_{t}$ and in part by an unobservable shock $\nu_{M t}$. Inflation is, then, perfectly determined by this monetary aggregate $\left(\pi_{t}=s_{M t}\right)$.

In the exchange rate regime, the signal $s_{E t}$ coincides with the action $a_{E t}\left(=e_{t}\right)$. Inflation is determined in part by the signal $s_{E t}$ and the shock to foreign inflation $\omega_{E t}\left(=\pi_{t}^{*}\right)$. The public perfectly observes the action of the central bank, but that action is only imperfectly related to inflation.

\section{IV.B. Multiple Monetary Aggregates}

Our model can be extended to include multiple monetary aggregates with differing levels of tightness and transparency. To do so, we let

$$
\begin{aligned}
& s_{j t}=\mu_{j t}+\varepsilon_{j t} \\
& \pi_{t}=s_{j t}+\nu_{j t},
\end{aligned}
$$

where $s_{j t}$ is the observed value of the monetary aggregate $j$ (M0, M1, M2, etc.), $\mu_{j t}$ is the intended value of the aggregate, $\varepsilon_{j t}$ is the control error with variance $\sigma_{\varepsilon j}^{2}$, and $\nu_{j t}$ is a veloc-

ity shock with variance $\sigma_{\nu j}^{2}$. Here the tightness of instrument $j$ is $\sigma_{\varepsilon j}^{2}+\sigma_{\nu j}^{2}$, and transparency is measured by $\sigma_{\varepsilon j}^{2}$. With commitment, the tightest instrument is preferred. Without commitment, the central bank trades off transparency and tightness in the same way it does in our comparison of exchange rates and a single monetary aggregate. In this sense, the tightness and transparency of the optimal monetary instrument vary with the environment and are endogenous.

\section{IV.C. Multiple Signals $\&$ An Observable Lag}

In modeling the idea that exchange rates are easier to monitor than money growth rates, we have made the simple but extreme assumptions that inflation is the only signal of the money growth rate and that intended money growth rates are never observed. Here we show that we can relax those assumptions - allow for multiple signals or for the money growth rate to be observed with a lag - and still find an advantage for transparency.

We begin with a second noisy signal of intended money growth. Here, similarly to our earlier model,

$$
s_{t}=a_{t}+\nu_{t},
$$


where $s_{t}$ is actual money growth, $a_{t}$ is intended money growth, and $\nu_{t}$ is a control error. We suppose now, however, that inflation is determined by intended money growth rather than actual money growth, in that

$$
\pi_{t}=a_{t}+\omega_{t}
$$

where $\omega_{t}$ is the linkage error. Note that agents now have two signals of intended money growth: $s_{t}$ and $\pi_{t}$.

Let $f(\pi, s \mid a)$ be the density of inflation $\pi$ and the noisy signal $s$ given the intended money growth rate $a$. Here the central bank's continuation value can vary only with $\pi$ and $s$ and can be written as $w(\pi, s)$. The central bank's incentive constraint now becomes

$$
\begin{aligned}
& (1-\beta) R(x, a)+\beta \iint w(\pi, s) f(\pi, s \mid a) d \pi d s \geq \\
& (1-\beta) R\left(x, a^{\prime}\right)+\beta \iint w(\pi, s) f\left(\pi, s \mid a^{\prime}\right) d \pi d s
\end{aligned}
$$

for any possible $a^{\prime}$. Proving the analog of Proposition 6 in this environment is straightforward.

Now suppose that while inflation is the only signal of the money growth rate that agents can observe in the current period, the intended money growth rate is perfectly observable with a lag; for simplicity, assume the lag is one period. Specifically, assume that the money growth rate $\mu_{t-1}$ is observed after agents set their wage in period $t$.

The intuition for why transparency is desirable in this environment is clear. Under the money regime, any deviation in period $t$ is not directly observed in that period. Thus, in period $t+1$, agents can react only to a noisy signal of that action. Of course, by period $t+2$, agents have observed the central bank's period $t$ action, and agents then can precisely react to any deviation in period $t$. This lag in the ability to react precisely leads to a tighter incentive constraint under the money regime and thus gives the transparent exchange rate regime its advantage.

The proof for the result that transparency has an advantage in this environment is similar to that for Proposition 6, with the exception that if the central bank discounts the future sufficiently little, then the incentive constraint in both regimes is slack, and both regimes can attain the Ramsey payoff. When the incentive constraint in both regimes is slack, there is no time inconsistency problem and, hence, no gain to transparency. 


\section{Concluding Remarks}

We have shown that the optimal choice of a monetary policy instrument depends on how tight and transparent the optional instruments are and on whether policymakers can or cannot commit to their future policies. Tightness is always desirable in an instrument, but transparency is desirable only when policymakers cannot commit. Interest rates thus have a natural advantage over money growth rates and exchange rates, because unlike those options, interest rates can be made endogenously tight. And both interest rates and exchange rates have a natural advantage over money growth rates because interest and exchange rates are more transparent. The general implication of our analysis is that (when all else is equal) the best monetary policy instrument is interest rates and the next-best is exchange rates. This implication provides some insight into the observed monetary policy instrument choices of developed and less-developed countries. 


\section{Notes}

${ }^{1}$ Canzoneri [1985] was the first to use the logic of Green and Porter [1984] to explain periodic bouts of high inflation. See also the work of Zarazaga [1995], who extends this logic, and Albanesi, Chari, and Christiano [2001], who use multiple Markov equilibria to obtain similar outcomes.

${ }^{2} \mathrm{~A}$ related literature uses signaling models to study the issue of transparency somewhat differently. Herrendorf [1999] considers an environment with two types of monetary authority: one with and one without a commitment technology. The monetary authority must choose between a transparent fixed exchange rate regime and an opaque floating exchange rate regime. Herrendorf shows that if the public has sufficiently strong beliefs that the monetary authority can commit, then both types of monetary authority choose the fixed exchange rate regime. We think of Herrendorf's model as applying to countries with governments that are likely to have the power to commit and, hence, do not face significant time inconsistency problems in monetary policy. In contrast, we think of our model as applying to countries with governments that have had chronic problems committing to good policies. Canavan and Tommasi [1997] explore a theme similar to that of Herrendorf [1999] in a model with unobserved types that are required to choose linear strategies. For related work in a domestic context, see the analysis of Backus and Driffill [1985].

There is also some work in this literature on the issue of transparency in monetary policy. Cukierman and Meltzer [1986] and Faust and Svensson [2001, 2002] explore linear signaling outcomes in models with unobserved types. 


\section{References}

Abreu, Dilip, David Pearce, and Ennio Stacchetti, "Optimal Cartel Equilibria with Imperfect Monitoring," Journal of Economic Theory, XXXIX (June 1986), 251-269. and "Toward a Theory of Discounted Repeated Games with Imperfect Monitoring," Econometrica, LVIII (September 1990), 1041-1063.

Adão, Bernardino, Isabel Correia, and Pedro Teles, "Monetary Policy with Single Instrument Feedback Rules," Manuscript, Bank of Portugal, 2006.

Albanesi, Stefania, V. V. Chari, and Lawrence J. Christiano, "How Severe Is the Time-Inconsistency Problem in Monetary Policy?" NBER Working Paper 8139, 2001.

Alesina, Alberto, and Robert J. Barro, "Currency Unions," Quarterly Journal of Economics, CXVII (May 2002), 409-436.

Backus, David, and John Driffill, "Inflation and Reputation," American Economic Review, LXXV (June 1985), 530-538.

Barro, Robert J., and David B. Gordon, "Rules, Discretion and Reputation in a Model of Monetary Policy," Journal of Monetary Economics, XII (July 1983), 101-121.

Bassetto, Marco, "A Game-Theoretic View of the Fiscal Theory of the Price Level," Econometrica, LXX (November 2002), 2167-2195.

Calvo, Guillermo A., and Carlos A. Végh, "Inflation Stabilization and BOP Crises in Developing Countries," in Handbook of Macroeconomics, Vol. 1C, John B. Taylor and Michael Woodford, eds. (Amsterdam: North-Holland, 1999), 1531-1614.

Canavan, Chris, and Mariano Tommasi, "On the Credibility of Alternative Exchange Rate Regimes," Journal of Development Economics, LIV (October 1997), 101-122.

Canzoneri, Matthew B., "Monetary Policy Games and the Role of Private Information," American Economic Review, LXXV (December 1985), 1056-1070.

Chang, Roberto, "Credible Monetary Policy in an Infinite Horizon Model: Recursive Approaches," Journal of Economic Theory, LXXXI (August 1998), 431-461.

Cukierman, Alex, and Allan H. Meltzer, "A Theory of Ambiguity, Credibility, and Inflation under Discretion and Asymmetric Information," Econometrica, LIV (September 1986), $1099-1128$.

Faust, Jon, and Lars E. O. Svensson, "Transparency and Credibility: Monetary Policy with 
Unobservable Goals," International Economic Review, XLII (May 2001), 369-397. , and , "The Equilibrium Degree of Transparency and Control in Monetary Policy," Journal of Money, Credit, and Banking, XXXIV (May 2002), 520-539.

Green, Edward J., and Robert H. Porter, "Noncooperative Collusion under Imperfect Price Information," Econometrica, LII (January 1984), 87-100.

Herrendorf, Berthold, "Importing Credibility Through Exchange Rate Pegging," Economic Journal, CVII (May 1997), 687-694.

, "Transparency, Reputation, and Credibility under Floating and Pegged Exchange Rates," Journal of International Economics, XLIX (October 1999), 31-50.

McCallum, Bennett T., "Price Level Determinacy with an Interest Rate Policy Rule and Rational Expectations," Journal of Monetary Economics, VIII (November 1981), 319-329.

Persson, Torsten, and Guido Tabellini, "Introduction," in Monetary and Fiscal Policy, Vol. 1, Credibility, Torsten Persson and Guido Tabellini, eds. (Cambridge, MA: MIT Press, 1994), 1-31.

Poole, William, "Optimal Choice of Monetary Policy Instruments in a Simple Stochastic Macro Model," Quarterly Journal of Economics, LXXXIV (May 1970), 197-216.

Sargent, Thomas J., and Neil Wallace, "'Rational' Expectations, the Optimal Monetary Instrument, and the Optimal Money Supply Rule," Journal of Political Economy, LXXXIII (April 1975), 241-254.

Stokey, Nancy L., " 'Rules versus Discretion' After Twenty-Five Years," in NBER Macroeconomics Annual 2002, Vol. 17, Mark Gertler and Kenneth Rogoff, eds. (Cambridge, MA: MIT Press/National Bureau of Economic Research, 2003), 9-45.

Woodford, Michael, Interest and Prices: Foundations of a Theory of Monetary Policy (Princeton, NJ: Princeton University Press, 2003).

Zarazaga, Carlos E. J. M., "Hyperinflations and Moral Hazard in the Appropriation of Seigniorage: An Empirical Implementation with a Calibration Approach," Federal Reserve Bank of Dallas Working Paper 95-17, 1995. 